\title{
Identification of Chromosomes Involved in Certain Translocation Lines of Pisum ${ }^{1}$
}

\author{
Kalloo ${ }^{2}$ \\ Department of Genetics and Plant Breeding, \\ Banaras Hindu University, U.P. India
}

Received March 5, 1971

Reciprocal translocations are an important tool for chromosome manipulation. They have been successfully used in transferring desirable characters from one species to another. Sears (1956) and Driscoll (1965) in wheat and Hagberg (1962) and Gustafsson (1965) in barley used translocation for breeding some of the desirable characters. It is a productive source of the production of duplications by intercrossing translocation involving the same chromosomes (Gopinath and Burnham 1965, Hagberg 1962). Translocation further provides new linkage relations by breaking undesirable association of genes. Recombination value was calculated from $\mathrm{F}_{2}$ date involving translocation in Pisum (Pellow 1940) and in barley (Hanson and Kramer 1950).

Some of the heterozygous translocations in Pisum were induced through gamma irradiation and studied in 1966-67 which are published elsewhere. They showed only a $\odot_{4}$ or a chain of four. Present investigation is carried out to study the chromosomes involved in six translocation lines by crossing with Lamm's translocation tester set.

\section{Material and methods}

Six heterozygous translocation lines were grown in $\mathrm{M}_{2}$ generation for the study. They segregated in the ratio of 1 semisterile and 1 fertile. In fertile group 50 percent plants are presumably translocation homozygotes and 50 percent homozygous normal. Some of the fertile plants in $\mathbf{M}_{2}$ generation, from each translocation line, were crossed with standard normal (control) and subsequently with Lamm's translocation tester set. $F_{1}$ plants were grown separately. $F_{1}$ plants (fertile $\times$ standard normal) showing sterility indicated fertile plants as translocation homozygote. Further, all $F_{1}$ plants (Translocation homozygotes $\times$ translocation testers), were studied cytologically. Sterility value of the plants showing above configurations was also recorded. A simple aceto-propiono carmine (1.5 percent) stain was used for the study.

Following translocation tester set was used for the study (Lamm and Miravalle 1959).

1 A part of the Ph.D. thesis.

2 Present address: Department of Vegetable Crops, Haryana Agricultural, University Hissar, India. 


\begin{tabular}{c|c|c|c|c|c|c}
\hline \hline Culture no. & 46 & 47 & 48 & 49 & 50 & 51 \\
\hline Translocation testers. & $\mathrm{T}(3-7) \mathrm{a}$ & $(\mathrm{T}(1-3) \mathrm{b}$ & $(\mathrm{T} 1-2) \mathrm{a}$ & $\mathrm{T}(5-6) \mathrm{a}$ & $\mathrm{T}(1-3) \mathrm{a}$ & $\mathrm{T}(6-7) \mathrm{a}$ \\
\hline
\end{tabular}

\section{Experimental findings and discussion}

$F_{1}$ plants of the crosses of fertiles (translocation homozygotes) with tester set were studied cytologically. The results are presented in Table 1.

Table 1. Identification of chromosomes involved in translocation homozygotes (Configurations and the degree of pollen sterility)

\begin{tabular}{|c|c|c|c|c|c|c|c|}
\hline \multirow{3}{*}{$\begin{array}{c}\mathbf{M}_{2} \text { culture } \\
\text { and plant } \\
\text { number }\end{array}$} & \multicolumn{6}{|c|}{ Testers culture number and the chromosomes involved } & \multirow{3}{*}{$\begin{array}{l}\text { Chromosomes } \\
\text { possibly involv- } \\
\text { ed in the } \\
\text { translocation }\end{array}$} \\
\hline & 49 & 50 & 47 & 46 & 49 & 51 & \\
\hline & $\mathrm{T}(1-2) \mathrm{a}$ & $T(1-3) a$ & $T(1-3) b$ & $\mathrm{~T}(3-7) \mathrm{a}$ & $T(5-6) a$ & $T(6-7) a$ & \\
\hline 1-1 & $\begin{array}{l}\bigcirc_{6}+41 \mathrm{II} \\
64.5 \%\end{array}$ & - & - & $\begin{array}{l}\bigcirc_{6}+4 \text { II } \\
71.6 \%\end{array}$ & $2 \odot_{4}+3^{I I}$ & $2 \odot_{4}+3^{\text {II }}$ & 1 and 3 \\
\hline $2-1$ & - & - & - & - & $\begin{array}{c}O_{6}+4^{I I I} \\
70 \%\end{array}$ & - & Either 5 or 6 \\
\hline $3-3$ & - & - & - & - & $\begin{array}{c}2 \mathrm{O}_{4}+3 \mathrm{II} \\
72 \%\end{array}$ & $\begin{array}{c}2 O_{4}+3 \text { II } \\
71 \%\end{array}$ & 3 and 4 \\
\hline $3-6$ & $\begin{array}{c}2 \bigcirc_{4}+3^{\mathrm{II}} \\
70.2 \%\end{array}$ & - & $\begin{array}{c}\Theta_{6}+4 I I \\
71 \%\end{array}$ & $\begin{array}{c}\bigcirc_{6}+4^{\mathrm{II}} \\
64 \%\end{array}$ & - & - & $\therefore$ \\
\hline $6-3$ & $\begin{array}{l}O_{6}+4 \mathrm{II} \\
60.4 \%\end{array}$ & $\begin{array}{c}20_{4}+4^{1 x} \\
70 \%\end{array}$ & - & $\begin{array}{c}2 \mathrm{O}_{4}+3^{\mathrm{II}} \\
71 \%\end{array}$ & $\begin{array}{c}\bigcirc_{6}+4{ }^{11} \\
69 \%\end{array}$ & $\begin{array}{c}2 \Theta_{4}+311 \\
65 \%\end{array}$ & 2 and 5 \\
\hline $7-2$ & - & - & - & - & - & $\begin{array}{c}2 \mathrm{O}_{4}+3^{1 I} \\
69 \%\end{array}$ & 2 and 4 \\
\hline $7-9$ & $\begin{array}{l}\bigcirc_{6}+4 \mathrm{II} \\
71.3 \%\end{array}$ & $\begin{array}{c}2 \mathrm{O}_{4}+3 \mathrm{II} \\
70.2 \%\end{array}$ & - & - & $\begin{array}{c}2 \odot_{4}+3 \text { II } \\
56 \%\end{array}$ & - & \\
\hline $8-6$ & $\begin{array}{c}2 \bigcirc_{4}+3 \text { II } \\
71.5 \%\end{array}$ & - & - & $\begin{array}{c}2 \odot_{4}+3 \mathrm{II} \\
61 \%\end{array}$ & - & - & \\
\hline $8-10$ & - & $\begin{array}{c}2 \odot_{4}+3^{\text {II }} \\
68 \%\end{array}$ & - & - & $\begin{array}{c}\bigcirc_{6}+4 \mathrm{II} \\
72 \%\end{array}$ & $\begin{array}{c}2 \mathrm{O}_{4}+3^{\mathrm{II}} \\
75 \%\end{array}$ & $\begin{array}{l}{ }^{4} \\
\vdots \ldots\end{array}$ \\
\hline
\end{tabular}

*V*

Plant 1-1 showed $2 \odot_{4}$ when crossed with $T(5-6) \mathrm{a}$ and $\mathrm{T}(6-7) \mathrm{a}$ indicating that chromosome 5, 6, 7 are not involved in the translocation. Crosses with T(1-2)a and T(3-7)a showed a $\odot_{6}$ revealing that the two possible chromosomes are 1 and 3 . This, however, needs confirmation.

Plant 2-1 was crossed successfully only with $\mathrm{T}(5-6)$ a. The $F_{1}$ showed $a \odot_{6}$. In the absence of other data conclusion arrived at is either chromosome 5 or 6 is involved in the reciprocal translocation. Identity of other chromosome is not known.

In the third set of crosses two plants 3-3 and 3-6 were considerably used. From the results (Table 1) chromosomes 1, 2, 5, 6 and 7 are not involved as $2 \odot_{4}$ were observed in the Crosses with $\mathrm{T}(1-2) \mathrm{a}, \mathrm{T}(5-6) \mathrm{a}$ and $\mathrm{T}(6-7) \mathrm{a} . \quad \mathrm{A} \odot_{6}$ was observed in the crosses with $T(1-3) b$ and $T(3-7) a$ indicating that chromosome 3 is involved in translocation. Chromosome 4 is evidently the other chromosome. 
In crosses involving plant $6-3,2 \odot_{4}$ were observed with $\mathrm{T}(1-3) \mathrm{a}, \mathrm{T}(3-7) \mathrm{a}$ and T(6-7)a indicating that chromosomes $1,3,6$ and 7 are not involved in translocation Crosses with $T(1-2) a$ and $T(5-6) a$ have given a $\odot_{6}$. This indicates that chromosomes 2 and 5 are involved in translocation as chromosome 1 and 6 are clearly eliminated from crosses with $\mathrm{T}(1-3) \mathrm{a}$ and $\mathrm{T}(6-7) \mathrm{a}$.

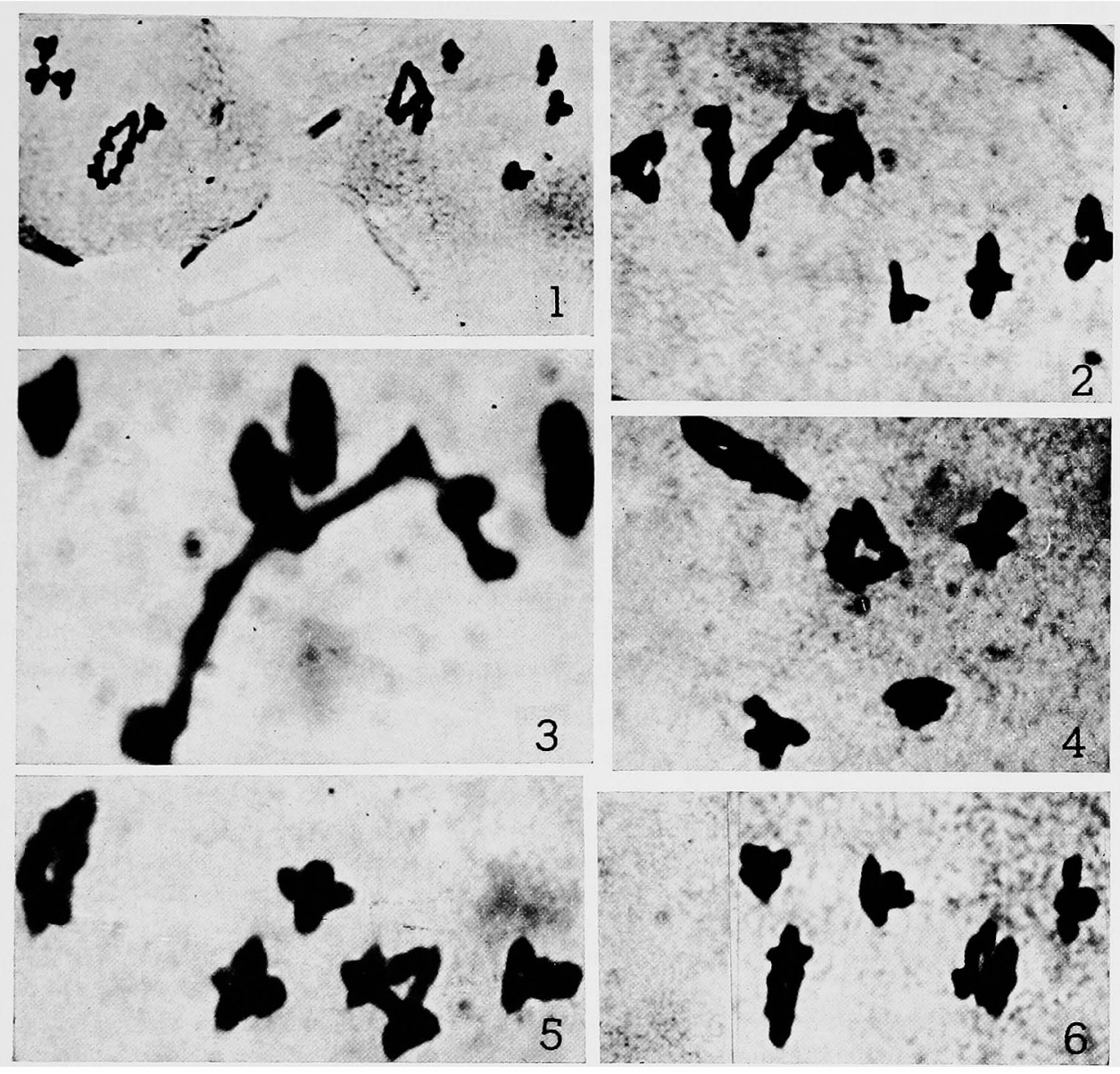

Figs. 1-6. 1, showing $\odot_{6}+4^{\mathrm{II}}$. 2, showing $\odot_{6}$ (Alternate) $+4^{\mathrm{II}}$. 3, a chain of $6+4^{\mathrm{Ir}} .4,2 \odot_{4}$ (Adjacent) $+3^{\text {II }}$. 5, 2๑ $\odot_{4}$ (One adjacent and other alternate) $+3^{\text {II }} .6,2 \odot_{4}+3^{\text {II }}$ (One alternate ring).

With regard to plants 7-2 and 7-9, crosses with $T(1-3) a, T(5-6) a$, and $T(6-7) a$ produced $2 \odot_{4}$. This indicates that chromosomes $1,3,5,6$ and 7 are not involved. A $\odot_{6}$ was observed with $\mathrm{T}(1-2)$ a which indicates that chromosome 2 is involved herein. The other chromosome is evidently 4 . There is some doubt in this case as in some crosses both configurations $2 \odot_{4}$ and $2 \odot_{6}$ were observed in the same plant. However, calculation was made on the basis of the configuration which was high in frequency.

In the set of crosses involving plants $8-6$ and $8-10$, all the crosses excepting 
with $\mathrm{T}(5-6) \mathrm{a}, 2 \odot_{4}$ were observed eliminating chromosomes $1,2,3,6$ and 7 . Since a $\odot_{6}$ was observed with $\mathrm{T}(5-6)$ a chromosome 5 appears to be involved in translocation. The other chromosome is evidently chromosome 4. Different types of $\odot_{6}$ (Figs. 1 and 2), Chain of Six (Fig. 3) and $2 \odot_{4}$ (Figs. 4, 5, and 6) were observed.

If $F_{1}$ of fertile (translocation homozygote) $\times$ tester, shows $7^{11}$ at metaphase $I$, the unknown translocation homozygote will involve the same two chromosomes as the tester. A ring of four may also be noted if the same chromosomes are involved but the segmental arrangement is different. On the other hand if $F_{1}$ shows $\odot_{6}$ it suggests that unknown translocation has one chromosome in common with the tester. However, if $F_{1}$ shows $2 \odot_{4}$, it indicates that both the chromosomes involved in the translocation are different from those in the tester set.

\section{Summary and conclusions}

Chromosomes involved in six interchange lines were identified using Lamm's translocation tester set. These chromosomes are 1 and 3, either 5 or 6,2 and 5, 2 and 4 , and 4 and 5 in different lines of interchange.

\section{Acknowledgements}

The author wishes to thank Dr. K. Das, Head, for his valuable suggestions and guidance. Thanks are also due to Dr. Robert Lamm and Council of Scientific and Industrial Research for providing the translocation tester set and financial assistance respectively.

\section{References}

Driscoll, C. J. 1965. Induced intergeneric transfers of chromosome segments. The use of Induced Mutations in Plant Breeding. FAO/IAEA Technical Meeting Rome: 727-739.

Gopinath, D. M. and Burnham, C. R. 1956. A cytogentic study in maize of deficiency-duplication produced by crossing interchanges involving the same chromosomes. Genetics 41: 382495.

Gustafsson, A. 1965. Characteristics and rates of high-productive mutants in diploid barley. The use of Induced Mutations in Plant Breeding. FAO/LAEA Technical Meeting Rome: 323-337.

Hagberg, A. 1962. Production of duplications in barley breeding. Hereditas 48: 243-246.

Hanson, W. D. and Kramer, H. H. 1950. The determination of linkage intensities from $F_{2}$ and $F_{3}$ genetic data involving chromosomal interchanges in barley. Genetics 35: 559-569.

Lamm, R. and Miravalle, R. J. 1959. A translocation tester set in Pisum. Hereditas 45: 417-440.

Pellew, C. 1940. Genetical studies on the first reciprocal translocation found in Pisum sativum. Jour. Cenet. 39: 363-390.

Sears, E. R. 1956. The transfer of leaf rust resistance from Aegilops umbellulata to wheat. Brookhaven Symposia in Biology. 9: Genetics in Plant Breeding: 1-22. 